\title{
GLASS FURNACE PROBLEMS
}

$\mathrm{T}$ THERE has been little advance in glass furnace design since the invention of the Siemens regenerative furnace in the sixties. Such improvements as have taken place have been largely in the resistance of the various refracturies to the temperature of which this type of furnace is capable, and even yet a producer-gas fired furnace can be run at a substantially higher temperature than the refractories themselves will withstand for long periods. The Society of Glass Technology, in cooperation with the Department of Glass Technology at the University of Sheffield, has given continuous thought to the problem of furnace design during the twenty-five years of its existence, and it was there. fore appropriate that the twenty-fifth anniversary meeting which was held at Sheffield on November 19 should take the form of a symposium on glass furnace problems.

The morning session was devoted to two papers dealing with the fundamental aspects of heat transmission, of which one, by Prof. D. T. A. Townend and his associates in the Department of Fuel at the University of Leeds, referred to radiation from flames and furmace linings, and the other, by Mr. J. B. Wagstaff, of Messrs. Hadfields, Ltd., had particular reference to the use of heat-resisting steels in recuperators. The second session, in the afternoon, dealt with the problem (of more immediate importance to the manufacturer) of the possibility of determining figures which would represent the performance of glass tank-furnaces, and provided a summary of the work which has been carried out by the Furnace Sub-Committee of the Department of Glass Technology during the last fow years.

In discussing the question of metal recuperators, it was pointed out that the conditions for heat exchange in gases are fundamentally different from those for liquids, in that there is a high temperature difference between ingoing and outgoing gases, and the large volume of gases to be considered travel necessarily at a low velocity. For temperatures below $600^{\circ} \mathrm{C}$., cast iron is reasonably satisfactory, and from that to $900^{\circ} \mathrm{C}$. alloy steels meet the case. Even the best alloy steels are unsatisfactory at temperatures in excess of about $900^{\circ} \mathrm{C}$, and the high nickel steels have the additional disadvantage that they are readily attacked by sulphur compounds. A metal recuperator, owing to the possibility of welding, can be made leak-proof, but the ordinary refractory recuperator, while standing up to the temperature and corrosion conditions, usually leaks so badly as to diminish its efficiency to a serious extent.

Mr. Wagstaff dealt in considerable detail with the fundamentals of the design of metal recuperators, and a point of considerable practical importance is the way in which the efficiency diminishes with a deposit of slag or dirt on the recuperator tubes. This was stated to be due to the increase in thermal resistance through the tube itself rather than to any change in the transfer of heat from the flame through the recuperator due to variations in the emissivity of the surface. In the course of the discussion it became clear that while some metal recuperators have failed in the course of as short a time as fortyeight hours, others have been found satisfactory for periods up to ten years; the main point that was emphasized being the necessity for selecting the metal appropriately to the particular conditions of the problem.

Prof. Townend provided a masterly summary of the fundamentals of heat transfer by radiation, and sketched in outline the theories that have been advanced to explain the radiation from water and carbon dioxide in the near infra-red. There is growing evidence of the existence of what he described as "over-activated molecules of relatively long life", which are, however, capable of giving up extra energy almost instantaneously on collision with the appropriate molecule or surface. Some of the facts which have led towards this conclusion are that silica-coated thermocouples record much lower temperatures than plain metallic thermocouples in the same gas stream, showing the effect of the surface on the rate of transfer. It has been shown also that most of the radiation from the Bunsen burner comes from the outer surface or the hot cone, indicating that all the energy is not instantaneously released on combustion. It is known that the addition of a small quantity of hydrogen to a carbon monoxide flame decreases the radiation disproportionately, but that the time of combustion increases. This was offered as a partial explanation of the known 'cutting' heat of a water-gas flame versus the 'soaking' heat of producer gas. In the flame spectrum of carbon monoxide there are bands superimposed on the continuous spectrum which are believed to be due to the over-activated molecules referred to above.

The effect of luminosity in the gas flame on the transfer of heat by radiation was then discussed by Prof. Townend. It has been shown that the radiation is greater than in the case of non-luminous flames but falls short of thrat emitted by a black body at the same temperature. Important factors in the rate of transfer in furnaces are the calorific value of the fuel as this affects the flame temperature, good mixing of the air and gas, and, related to this, the turbulence of flow. The point that is sometimes overlooked by the practical man is that the flame must always be considerably hotter than the walls of the closure.

Prof. Townend's colleague, Dr. A. L. Roberts, discussed the question of the radiation from solids, and pointed out that most refractory materials are initially selective radiators, and showed diagrams indicating how the purity of the refractory material affects the flame and its emissivity curve. Contamination of the surface of refractories in use tends to make them less selective, whereas the most hopeful lines of research would appear to be to make the walls radiate selectively so that the energy would be mostly radiated in the region where it could be most easily absorbed by the substance to be melted. The texture of the surface also has an important bearing on the effective emissivity. Rough surfaces have higher effective values although they, again, tend to render the radiation less selective. There are, therefore, two contradictory facts, and only experience can show which of them has the most important bearing on flame transfer efficiency.

The afternoon papers were, as stated earlier, more largely of direct interest to the glass manufacturer. Mr. W. A. Moorshead summarized the principles involved in the calculation of furnace performances 
with particular reference to the effect of changes in regenerator efficiency on the thermal balance sheet. Dr. W. M. Hampton put forward a proposal for a performance figure for glass tank furnaces. While the accurate determination of a thermal balance sheet provides all the information necessary, it involves so much time and work that some simplified method of calculation is anxiously required. It has been the custom in the glass industry to consider the simple ratio glass made/coal used, but it was pointed out that the amount of glass produced in a furnace bears no necessary relation to the amount of glass such a furnace is capable of molting, as commercial considerations frequently come into operation. It is clear that the fuel consumption of a furnace increases with the throughput of glass, and after considering many alternative bases for comparison, it has now been agreed by the Furnace Committee that the fuel consumptions of different furnaces should be compared on the 'no load' basis, that is, the amount of coal needed to maintain the furnace at a given temporature when it is not actually producing any glass. Since the fuel consumption also varies with the temperature at which the furnace is run, Dr. Hampton proposed-and curves were provided to enable the transformation to be carried out simply-that the fuel consumption should be calculated as at a standard temperature of $1400^{\circ} \mathrm{C}$.

It has also now been agreed by the Furnace Committee that the input to the furnace should bo reckoned in heat units instead of in terms of various fuels, and the proposed performance figure suggested as the area of the furnace per unit input of heat which can be maintained at a temperature of $1400^{\circ} \mathrm{C}$. when no glass is being produced. Using the informa. tion collected by the Department of Glass Technology over the last four years on glass tank furnaces in various parts of Great Britain, it was shown that there is a definite correlation between the size of the furmace and its performance figure, and also that the most important factor in improving the performance is adequate insulation. Differences in design are apparently of minor importance.

The general impression left by the meeting and discussion was that the glass industry is fully alive to the necessity for fundamental research, and that by the use of some agreed basis it should be possible to compare the performance of tank furnaces employed in making very widely different types of glass. Such comparisons should enable the effect of variations in design or materials on the performance of furnaces to be estimated, and so lead to substantial improvements in fuel economy.

W. M. HaMpton.

\section{CIVILIZATIONS IN TRANSITION}

A LTHOUGH cultural penetrations usually follow predictable lines in accordance with proximity, degree of difference between the civilizations involved, and their relative prestige values, notable exceptions indicate the wide variability of human reactions.

In the symposium on "Civilizations in Transition", held on September 25 as par't of the celebration of the fiftieth anniversary of the University of Chicago, Prof. Robert H. Lowie, professor of anthropology in the University of California, and Prof. Michael I. Rostovtzeff, professor of ancient history in Yale University, discussed phases of cultural infiltration.

Prof. Rostovtzeff, speaking on "The Destinies of Hellenism in the Near East", described the trends toward hegemony and toward subordination which existed simultaneously in the case of the Greek settlers in Egypt. At first the Greeks, bearers of a high culture, were an élite, organizing a complex bureaucracy which virtually undermined the royal power and which milked the native population of its wealth. Later, Prof. Rostovtzeff said, the tendencies towards cultural acclimatization began to take effect, and by the time of the rise of Roman power, the Greek creative force in Egypt had been exhausted.

After the death of Alexander the Great, a wave of Greek emigrants swept into Egypt.

Since the status of the Greeks was that of a privileged class, the higher strata of the native population naturally tried to acquire for themselves this status. The prerequisite for it was Greek education and participation in Greek life. Thus a certain part of the native population became gradually 'Hellenized' and some of them received from the king the status of Hellenes.

Prof. Lowie discussed numerous examples of primitive groups in which cultural transfer depended on such obvious factors as the conqueror-conquered relationship and geographical proximity, but also listed situations in which these factors were outweighed by customs and other cultural phenomena which prevented transfer of traits of civilization when other circumstances were apparently favourable. Speaking on "The Transition of Civilizations in Primitive Societies", he also pointed to societies in which culture spread from the conquered to the conqueror and across apparently insuperable geographical barriers.

Although contact between two cultures usually results in an exchange of cultural traits, it does not always have this result. Dr. Lowie cited as an example four tribes in the Nilgiri Hills of southern India all of which live within easy walking distance of one another. The Toda are buffalo-breeders; the Badaga raise millet; the Kota serve as smiths and musicians; the food-gathering Kurumba practise magic. Transference of traits among the tribes is inhibited by the intense caste sentiment that prevails. When a few Kota attempted to wear turbans, after the fashion of the Badaga, they were at once beaten up by their outraged neighbours. Geographically there is an ideal set-up for a levelling of cultural differences, but any such process is frustrated by the prevailing ideology.

Class consciousness hinders the free spread of ideas by checking one of its most natural promoters, intermarriage; and it is equally potent when material advantages are reserved to a dominant people.

In Ankole, an East African country, the subject Bairu cannot turn into independent stock-breeders so long as their Bahima overlords claim the right to own all productive cows. Another factor preventing exchange of traits is the emotional revulsion to a novelty which, however useful, flouts accepted 